TITLE:

\title{
Bimodal nanoporous platinum on sacrificial nanoporous copper for catalysis of the oxygen-reduction reaction
}

\section{$\operatorname{AUTHOR}(\mathrm{S})$ :}

Hakamada, Masataka; Sato, Yuto; Mabuchi, Mamoru

\section{CITATION:}

Hakamada, Masataka ... [et al]. Bimodal nanoporous platinum on sacrificial nanoporous copper for catalysis of the oxygen-reduction reaction. MRS Communications 2019, 9(1): 292-297

\section{ISSUE DATE:}

2019-03

URL:

http://hdl.handle.net/2433/237616

\section{RIGHT:}

This article has been published in a revised form in 'MRS Communications', https://doi.org/10.1557/mrc.2018.223. This version is free to view and download for private research and study only. Not for re-distribution, re-sale or use in

derivative works. @ Materials Research Society; The full-text file will be made open to the public on 1 September 2019 in accordance with publisher's 'Terms and Conditions for Self-Archiving'.; この論文は出版社版でありません。引用の際 には出版社版をご確認ご利用ください。; This is not the published version. Please cite only the published version. 


\title{
Bimodal nanoporous platinum on sacrificial nanoporous copper for catalysis of oxygen-reduction reaction
}

\author{
Masataka Hakamada*, Yuto Sato and Mamoru Mabuchi \\ Department of Energy Science and Technology, Graduate School of Energy Science, Kyoto University, \\ Yoshidahonmachi, Sakyo, 606-8501 Kyoto, Japan \\ * Corresponding author. E-mail: hakamada.masataka.3x@kyoto-u.ac.jp (M. Hakamada).
}

\begin{abstract}
Bimodal nanoporous platinum (BNP-Pt) is synthesized by using a sacrificial nanoporous copper (NP-Cu) support for oxygen-reduction-reaction (ORR) catalysts in fuel cells. The specific ORR catalytic activity of BNP-Pt increases by the dissolution and removal of supporting NP-Cu, suggesting that the BNP structure improves the intrinsic catalytic properties of platinum. The lattice contraction of BNP-Pt containing residual copper even after NP-Cu removal is milder than predicted by Vegard's law. The BNP structure governs the intrinsic catalytic activity of the platinum by relaxing the lattice contraction and by alloying with copper and/or misfit strain at the $\mathrm{Pt} / \mathrm{Cu}$ interface.
\end{abstract}

Keywords: Pt; nanostructure; surface reaction 


\section{Introduction}

Platinum is used as a catalytic electrode in fuel cells. Fuel-cell performance is often governed by the oxygen-reduction reaction (ORR) at an air electrode made of platinum. ${ }^{[1]}$ Platinum is a rare metal and is found disproportionately in the earth's crust. Hence, the platinum price is high and fluctuates, which prevents fuel cells from being used widely. Many efforts have been made to improve the catalytic activity of platinum in the ORR. One strategy is nanostructuring of platinum; that is, a reduction in the typical length scale of platinum is advantageous in terms of an effective surface area. Platinum nanoparticles ${ }^{[2,3]}$ and hollow platinum nanoparticles are good candidates for efficient ORR catalytic electrodes. ${ }^{[4,5]}$

On the other hand, synthesis of nanoporous metals by dealloying or selective dissolution of one element from a binary alloy is another strategy for nanostructuring. Such a three-dimensional nanoporous structure is obtained in various metals. ${ }^{[6,7]}$ Nanoporous copper (NP-Cu) can be also produced by dealloying ductile $\mathrm{Cu}-\mathrm{Mn}$ alloys, ${ }^{[8-10]}$ and similarly, porous Raney copper is synthesized by dealloying $\mathrm{Cu}-\mathrm{Al}$ alloys. ${ }^{[11]}$

Platinum can be deposited in the form of a dense film or fine particles on copper by electroless plating or galvanic replacement. ${ }^{[5,12]}$ Thus, NP-Cu can be converted to nanoporous platinum with a skeletal structure replicated from NP-Cu and deposits of fine platinum particles. The supporting NP-Cu can be removed readily by $\mathrm{HNO}_{3}$ which dissolves copper selectively out through the porous particulate platinum layer, and leaves a bimodal nanoporous platinum (BNPPt) (Fig. 1a). Here we show the synthesis of BNP-Pt for ORR by electroless plating of platinum on the sacrificial NP-Cu and subsequent dissolution of NP-Cu. We focus on the contraction of 
the crystal lattice of platinum in BNP-Pt as a source of high ORR catalytic activity per surface area.

\section{Material and methods}

Initial $\mathrm{Cu}_{0.3} \mathrm{Mn}_{0.7}$ alloy button-shaped ingots were fabricated by the arc melting of pure copper and manganese in an argon atmosphere. After heating at $1123 \mathrm{~K}$ for $24 \mathrm{~h}$ in an Ar atmosphere, the alloy ingot was water-quenched, ${ }^{[13]}$ followed by cold rolling to $0.2-\mathrm{mm}$ thickness.

Dealloying to fabricate NP-Cu was conducted by free corrosion in $1 \mathrm{~mol} \mathrm{~L}{ }^{-1} \mathrm{HCl}$ for $24 \mathrm{~h}$, where manganese was dissolved selectively and copper formed a nanoporous structure spontaneously (Fig. 1b). ${ }^{[8-10]}$ After washing in pure water, the NP-Cu working electrode was pulverized manually in an agate bowl to a powder.

NP-Cu $(0.05 \mathrm{~g})$ was mixed with $1 \mathrm{~g}$ of $5 \mathrm{wt} \%$ Nafion ethanolic solution and $5 \mathrm{~g}$ of water. After homogenization in an ultrasonic bath, this suspension was fixed on a glassy carbon (GC) rotation disk electrode (RDE) with 5-mm diameter. The displacement deposition of platinum on the fixed NP-Cu was conducted by immersing the GC RDE in $1 \mathrm{mmol} \mathrm{L}^{-1} \mathrm{H}_{2} \mathrm{PtCl}_{4}$ aqueous solution at $273 \mathrm{~K}$ for $1 \mathrm{~h}$ at $600 \mathrm{rpm} .{ }^{[14]}$ Thus, the GC electrode includes NP-Cu with a fine platinum deposition. The GC electrode that includes BNP-Pt was immersed in $0.1 \mathrm{~mol} \mathrm{~L}^{-1} \mathrm{HNO}_{3}$ for 24 $\mathrm{h}$ to dissolve the copper.

We conducted cyclic voltammetry (CV) at room temperature by using the GC electrode loading BNP-Pt as a working electrode. To evaluate the electrochemical surface area (ECSA) of the BNP-Pt samples, CV was conducted in degassed $0.5 \mathrm{~mol} \mathrm{~L}^{-1} \mathrm{H}_{2} \mathrm{SO}_{4}$ with a scan rate of $10 \mathrm{mV}$ 
$\mathrm{s}^{-1}$. A reversible hydrogen electrode (RHE) and Pt wire were used as a reference and counter electrode, respectively. For electrochemical cleaning, CV was repeated until a steady currentpotential cyclic curve was attained. The charge that is associated with hydrogen adsorption $\left(Q_{\mathrm{H}}\right)$ was calculated by using the cathodic peak between 0.1 and $0.35 \mathrm{~V}$ (vs. RHE), which was then converted to the ECSA $(A)$ of the sample: ${ }^{[15]}$

$$
A_{\text {sample }} / A_{\text {bulk }}=Q_{\mathrm{H}, \text { sample }} / Q_{\mathrm{H}, \mathrm{bulk}}
$$

where the subscripts "sample" and "bulk" represent the BNP-Pt and bulk platinum, respectively.

The working GC-RDE-loaded BNP-Pt was rotated for ORR activity measurements during the $\mathrm{CV}$ in an electrolyte of $\mathrm{O}_{2}$-saturated $0.1 \mathrm{~mol} \mathrm{~L}^{-1} \mathrm{H}_{2} \mathrm{SO}_{4}$ with a scan rate of $10 \mathrm{mV} \mathrm{s}^{-1}$. The kinetically-controlled current $i_{\mathrm{K}}$, which is an index of the ORR activity of the BNP-Pt, was calculated according to:

$$
1 / i=1 / i_{\mathrm{K}}+1 / B \omega^{1 / 2}
$$

where $i$ is a measured current; $B$ is a constant and $\omega$ is the RDE rotation speed. $i_{\mathrm{K}}$ was derived from the intersection at $\omega^{-1 / 2}=0$ by the Koutechy-Levich plot of $i^{-1}$ (at $0.65 \mathrm{~V}$ vs. RHE) against $\omega^{-1 / 2} \cdot{ }^{[16-19]}$ The specific activity per ECSA was calculated by dividing $i_{\mathrm{K}}$ by $A_{\text {sample }}(\mathrm{ECSA})$.

Substances on the GC RDE were collected for SEM, scanning transmission electron microscopy (STEM) and high-resolution transmission electron microscopy (HR-TEM). Energy-dispersive X-ray spectroscopy (EDXS) was used for elemental analyses in the microscopic observations. X-ray diffraction (XRD) patterns of samples (and conventional Pt black) were collected under a parallel-beam configuration at $298 \mathrm{~K}$. The concentration of platinum and other elements in 
samples was determined by inductively-coupled plasma atomic emission spectroscopy (ICPAES) after dissolving the samples in $20 \mathrm{~mL}$ of nitrohydrochloric acid.

\section{Results and discussion}

STEM images (Fig. 2) indicate the bimodal structure of the sample. The nanoporous hollow structure with an average pore diameter of $23 \mathrm{~nm}$ (Fig. 2a), which is replicated from NP-Cu (Fig. 1b), was composed of finer Pt particles with 3-5 nm diameters (Figs. 2b and 2c). STEM-EDXS reveals that $\mathrm{Cu}$ remains even after dissolution by $\mathrm{HNO}_{3}$, although $\mathrm{Cu}$ and $\mathrm{Pt}$ exhibited a homogeneous distribution without surface segregation (Fig. 2d). The remaining $\mathrm{Cu}$ in the sample after dissolution by $\mathrm{HNO}_{3}$ was confirmed by SEM-EDXS (Fig. 3a), where the atomic ratio of $\mathrm{Cu} / \mathrm{Pt}$ was 11.5 before dissolution and 0.54 after dissolution. On the other hand, manganese was not detected by EDXS and ICP-AES in BNP-Pt before and after the dissolution of copper. Thus, the contribution of manganese is eliminated in the following discussion on the catalytic properties of BNP-Pt samples.

XRD patterns of BNP-Pt before and after copper dissolution are shown in Fig. 3b. Before copper dissolution, the broad peaks for platinum are accompanied by peaks for metallic copper and copper oxide $\left(\mathrm{Cu}_{2} \mathrm{O}\right)$. Minor $\mathrm{Cu}_{2} \mathrm{O}$ appears to form during the preparation of NP-Cu by dealloying. Metallic copper and $\mathrm{Cu}_{2} \mathrm{O}$ were not detected after dissolution by $\mathrm{HNO}_{3}$. Core NP$\mathrm{Cu}$ and accompanying minor $\mathrm{Cu}_{2} \mathrm{O}$ dissolved into $\mathrm{HNO}_{3}$, whereas Pt remained undissolved. An inspection of the XRD patterns showed that the peaks of Pt in BNP-Pt shifted to higher diffraction angles compared with referenced Pt black.

CV curves for BNP-Pt before and after copper dissolution (Fig. 4a) are typical for platinum ${ }^{[14-19]}$ 
with peaks for hydrogen and oxygen adsorption/desorption. Copper dissolution by $\mathrm{HNO}_{3}$ caused no significant change in the redox process during CV scanning.

The ORR activity of the BNP-Pt samples was examined by RDE (Fig. 4b). In the polarization curves, the current density at a high potential of $1.1 \mathrm{~V}$ was independent of the electrode rotation rate, which corresponds to the kinetic region of the ORR. As the potential decreased from 1.1 $\mathrm{V}$, transitional regions from a kinetic- to a diffusion-controlled reaction rate were observed, with a lower current density at a higher electrode rotation rate. Below $0.4 \mathrm{~V}$, the current density was almost constant and a diffusion-controlled reaction occurred.

The specific activities of BNP-Pt per ECSA of Pt before and after copper dissolution were 1.48 and $4.18 \mathrm{~mA} \mathrm{~cm}^{-2}$, respectively, according to the RDE results. On the other hand, activity per mass of BNP-Pt before and after copper dissolution was 0.14 and $0.35 \mathrm{~A} \mathrm{mg}_{\mathrm{Pt}}{ }^{-1}$, respectively. These values are significantly higher than those of the conventional $\mathrm{Pt} / \mathrm{C}^{[17]}$ and comparable with the values reported recently for other nanoporous Pt-based alloys. ${ }^{[1,20-25]}$ Furthermore, the copper dissolution increased the specific activity of the BNP-Pt. Above all, a higher activity per ECSA (and not per mass or geometric area) for BNP-Pt after copper dissolution means that the intrinsic catalytic nature of the platinum is enhanced by the disappearance of the supporting skeletal NP-Cu, although the overpotential itself is not so different between the two BNP-Pt samples.

Lattice straining affects the overall catalytic performance in platinum. ${ }^{[1,26,27]}$ Strasser et al. ${ }^{[21]}$ discuss the effect of lattice strain on the activity of core-shell platinum catalysts for ORR, where the Pt-Cu nanoparticles are dealloyed partially to form nanoparticles with a platinum shell and 
a $\mathrm{Pt}-\mathrm{Cu}$ core. A moderate reduction in lattice constant, namely, lattice contraction of the platinum is important to enhance the ORR activity of the platinum, although an excessive compressive lattice strain (approximately below $-2.5 \%$ ) deteriorates the ORR activity. Table 1 shows the lattice constants of BNP-Pt calculated from the XRD peaks (Fig. 3a). The lattice constants of the BNP-Pt before and after copper dissolution were lower than those of the bulk platinum, which suggests that misfit strain and/or alloying occurs during the displacement electrodeposition of platinum on NP-Cu. The reduction in lattice constants is milder in the BNP-Pt after copper dissolution than in the BNP-Pt before copper dissolution. This moderate lattice contraction in BNP-Pt after copper dissolution is responsible for the improved ORR activity per ECSA. A partial dissolution of supporting NP-Cu from BNP-Pt leads to a relaxation of the misfit strain that is generated between the platinum shell and the copper core.

The SEM-EDXS showed that the residual copper in the BNP-Pt is not negligible even after immersion in $\mathrm{HNO}_{3}$. According to Vegard's law, lattice constant $a$ is supposed to be $3.815 \mathrm{~nm}$ for $\mathrm{Pt}_{0.65} \mathrm{Cu}_{0.35}$ (BNP-Pt after copper dissolution), which is smaller than the present value (Table 1). That is, the lattice contraction is milder than expected from the atomic ratio of $\mathrm{Pt} / \mathrm{Cu}$ and Vegard's law. After copper dissolution, other copper-containing phases in the BNP-Pt were not detected by XRD (Fig. 3a). The STEM-EDXS also showed no significant distribution and separation of copper and platinum. These results indicate that the nanoporous and replicated hollow structure intrinsically cause a peculiar lattice straining due to the large positive and negative curvatures. ${ }^{[28,29]}$ Nanoporous nickel that is fabricated by dealloying of $\mathrm{Ni}-\mathrm{Mn}$ alloys shows larger lattice constants than those in bulk nickel. ${ }^{[30]}$ Similarly, the nanoporous and replicated structure may relax the severe lattice compression in BNP-Pt expected by Vegard's 
law.

Further discussion on the ORR performance of BNP-Pt requires determination of active site density, turnover frequency, crystallographic structure, and chemical (oxidation) state of BNPPt. The Brunauer-Emmett-Teller (BET) measurement, extended X-ray absorption fine structure (EXAFS) analysis, X-ray photoelectron spectroscopy (XPS) are useful tools; nevertheless, the specific activity per ECSA is a first parameter representative for performance of ORR. Also, the role of copper in the straining and subsequent catalysis on ORR is not fully understood at this stage. There is much room for investigation.

\section{Conclusions}

BNP-Pt catalysts for ORR were fabricated by using NP-Cu as a sacrificial metallic support. The high ORR specific activity of BNP-Pt after copper dissolution is attributed to the moderate lattice contraction in platinum, which is induced by alloying with copper and/or a misfit strain at the $\mathrm{Pt} / \mathrm{Cu}$ interfaces, but which is relaxed by the replicated nanoporous hollow structure.

\section{Acknowledgments}

M. H. acknowledges financial support by Kansai Research Foundation for Technology Promotion. TEM and STEM observations were conducted at the Kyoto University Nano Technology Hub in the "Nanotechnology Platform Project" sponsored by the Ministry of Education, Culture, Sports, Science and Technology (MEXT), Japan. 


\section{References}

[1] I. E. L. Stephens, A. S. Bondarenko, U. Grønbjerg, J. Rossemeisl, and I. Chorkendorff: Understanding the electrocatalysis of oxygen reduction on platinum and its alloys. Energy Environ. Sci. 5, 6744 (2012).

[2] K. Wikander, H. Ekström, A. E. C. Palmqvist, and G. Lindbergh: On the influence of Pt particle size on the PEMFC cathode performance. Electrochim. Acta 52, 6848 (2007).

[3] M. Li, Z. Zhao, T. Cheng, A. Fortunelli, C.-Y. Chen, R. Yu, Q. Zhang, L. Gu, B. V. Merinov, Z. Lin, E. Zhu, T. Yu, Q. Jia, J. Guo, L. Zhang, W. A. Goddard III, Y. Huang, and X. Duan: Ultrafine jagged platinum nanowires enable ultrahigh mass activity for the oxygen reduction reaction. Science 354, 1414 (2016).

[4] H. Wang, S. Xu, C. Tsai, Y. Li, C. Liu, J. Zhao, Y. Liu, H. Yuan, F. Abild-Pedersen, F. B. Prinz, J. K. Nørskov, and Yi Cui: Direct and continuous strain control of catalysts with tunable battery electrode materials. Science 354, 1031 (2016).

[5] Y. Zhang, C. Ma, Y. Zhu, R. Si, Y. Cai, J. X. Wang, and R. A. Adzic: Hollow core supported Pt monolayer catalysts for oxygen reduction. Catal. Today 202, 50 (2013).

[6] A. J. Forty: Corrosion micromorphology of noble metal alloys and depletion gilding. Nature 282, 597 (1979).

[7] D. V. Pugh, A. Dursun, and S. G. Corcoran: Formation of nanoporous platinum by selective dissolution of $\mathrm{Cu}$ from $\mathrm{Cu}_{0.75} \mathrm{Pt}_{0.25}$. J. Mater. Res. 18, 216 (2003). 
[8] D. S. Keir and M. J. Pryor: The dealloying of copper-manganese alloys. J. Electrochem. Soc. 127, 2138 (1980).

[9] U.-S. Min and J. C. M. Li: The microstructure and dealloying kinetics of a Cu-Mn alloy. J. Mater. Res. 9, 2878 (1994).

[10] J. R. Hayes, A. M. Hodge, J. Biener, A. V. Hamza, and K. Sieradzki: Monolithic nanoporous copper by dealloying Mn-Cu. J. Mater. Res. 21, 2611 (2006).

[11] X. Kong, C. Ma, J. Zhang, J. Sun, J. Chen, and K. Liu: Effect of leaching temperature on structure and performance of Raney $\mathrm{Cu}$ catalysts for hydrogenation of dimethyl oxalate, Appl. Catal. A-Gen. 509, 153 (2016).

[12] Q. Feng, S. Liu, Z. Wang, and G. Jin: Nanoporous copper incorporated platinum composites for electrocatalytic reduction of $\mathrm{CO}_{2}$ in ionic liquid BMIMBF 4 . Appl. Surf. Sci. 258, 5005 (2012).

[13] H. Okamoto: Cu-Mn (Copper-Manganese). J. Phase Equilib. 19, 180 (1998).

[14] E. J. Coleman and A. C. Co: Galvanic displacement of Pt on nanoporous copper: An alternative synthetic route for obtaining robust and reliable oxygen reduction activity. J. Catal. 316, 191 (2014).

[15] S. Trasatti and O. A. Petrii: Real surface area measurements in electrochemistry. J. Electroanal. Chem. 327, 353 (1992).

[16] Y. Garsany, O. A. Baturina, K. E. Swider-Lyons, and S. S. Kocha: Experimental methods for quantifying the activity of platinum electrocatalysts for the oxygen reduction reaction. Anal. 
Chem. 82, 6321 (2010).

[17] J. Hu, K. A. Kuttiyiel, K. Sasaki, D. Su, T.-H. Yang, G.-G. Park, C. Zhang, G. Chen, and R. R. Adzic: Pt monolayer shell on nitrided alloy core—a path to highly stable oxygen reduction catalyst. Catalysts 5, 1321 (2015).

[18] L.-L. He, P. Song, A.-J. Wang, J.-N. Zheng, L.-P. Mei, and J.-J. Feng: A general strategy for the facile synthesis of $\mathrm{AuM}(\mathrm{M}=\mathrm{Pt} / \mathrm{Pd})$ alloyed flowerlike-assembly nanochains for enhanced oxygen reduction reaction. J. Mater. Chem. A 3, 5352 (2015).

[19] J.-N. Zheng, L.-L. He, F.-Y. Chen, A.-J. Wang, M.-W. Xue, and J.-J. Feng: Simple one-pot synthesis of platinum-palladium nanoflowers with enhanced catalytic activity and methanoltolerance for oxygen reduction in acid media, Electrochim. Acta 137, 431 (2014).

[20] R. Cui, L. Mei, G. Han, J. Chen, G. Zhang, Y. Quan, N. Gu, L. Zhang, Y. Fang, B. Qian, Z. Jiang, and Z. Han: Facile synthesis of nanoporous Pt-Y alloy with enhanced electrocatalytic activity and durability. Sci. Rep. 7, 41826 (2016).

[21] P. Strasser, S. Koh, T. Anniyev, J. Greeley, K. More, G. Yu, Z. Liu, S. Kaya, D. Nordlund, H. Ogasawara, M. F. Toney, and A. Nilsson: Lattice-strain control of the activity in dealloyed coreshell fuel cell catalysts. Nat. Chem. 2, 454 (2010).

[22] L. Bu, Q. Shao, B. E, J. Guo, J. Yao, and X. Huang: PtPb/PtNi intermetallic core/atomic layer shell octahedra for efficient oxygen reduction electrocatalysis. J. Am. Chem. Soc. 139, 95769582 (2017). 
[23] B.-A. Lu, T. Sheng, N. Tian, Z.-C. Zhang, C.Xiao, Z.-M. Cao, H.-B. Ma, Z.-Y. Zhou, and S.G. Sun: Octahedral PtCu alloy nanocrystals with high performance for oxygen reduction reaction and their enhanced stability by trace Au. Nano Energy 33, 65 (2017).

[24] J. Park, M. K. Kabiraz, H. Kwon, S. Park, H. Baik, S.-I. Choi, and K. Lee: Radially phase segregatedPtCu@PtCuNi dendrite@frame nanocatalyst for the oxygen reduction reaction.ACS Nano 11, 10844 (2017).

[25] F. Godínez-Salomón, R. Mendoza-Cruz, M. J. Arellano-Jimenez, M. Jose-Yacaman, and C. P. Rhodes: Metallic two-dimensional nanoframes: unsupported hierarchical nickel-platinum alloy nanoarchitectures with enhanced electrochemical oxygen reduction activity and stability. ACS Appl. Mater. Interf. 9, 18660 (2017).

[26] F. M. F. Rhen and C. McKeown: Enhanced methanol oxidation on strained Pt films. J. Phys. Chem. C 121, 2556 (2017).

[27] H. A. Gasteiger, S. S. Kocha, B. Sompalli, and F. T. Wagner: Activity benchmarks and requirements for Pt, Pt-alloy, and non-Pt oxygen reduction catalysts for PEMFCs. Appl. Catal. B-Environ. 56, 9 (2005).

[28] M. Hakamada, H. Nakano, T. Furukawa, M. Takahashi, and M. Mabuchi: Hydrogen storage properties of nanoporous palladium fabricated by dealloying. J. Phys. Chem. C 114, 868 (2010).

[29] T. Fujita, P. Guan, K. McKeena, X. Y. Lang, A. Hirata, L. Zhang, T. Tokunaga, S. Arai, Y. Yamamoto, N. Tanaka, Y. Ishikawa, N. Asao, Y. Yamamoto, J. Erlebacher, and M. W. Chen: Atomic origins of the high catalytic activity of nanoporous gold. Nat. Mater. 11, 775 (2012). 
[30] M. Hakamada, M. Takahashi, T. Furukawa, and M. Mabuchi: Surface effects on saturation magnetization in nanoporous Ni. Philos. Mag. 90, 1915 (2010). 


\section{Tables}

Table 1. Lattice constants of platinum in bimodal nanoporous platinum.

\begin{tabular}{ccc}
\hline & \multicolumn{2}{c}{ Lattice constant $a(\mathrm{~nm})$ and change from that in bulk platinum } \\
Plane index & $\left(a_{\text {bulk Pt }}=3.923 \mathrm{~nm}\right)$ \\
& Before Cu dissolution & After Cu dissolution \\
\hline 111 & $3.829(-2.40 \%)$ & $3.849(-1.89 \%)$ \\
200 & $3.828(-2.42 \%)$ & $3.836(-2.22 \%)$ \\
220 & $3.831(-2.36 \%)$ & $3.832(-2.33 \%)$ \\
311 & $3.840(-2.12 \%)$ & $3.842(-2.06 \%)$ \\
\hline Average & $3.832(-2.32 \%)$ & $3.840(-2.13 \%)$ \\
\hline
\end{tabular}




\section{Figure captions}

Figure 1. (a) Schematic illustration of synthesis of bimodal nanoporous platinum using nanoporous copper as a sacrificial support. (b) Scanning electron microscopy image of nanoporous copper fabricated by dealloying of $\mathrm{Cu}-\mathrm{Mn}$ alloy.

Figure 2. Scanning transmission electron microscopy (a, b, d) and high-resolution transmission electron microscopy (c) images of bimodal nanoporous platinum. Panels a, b and left panel in d are high-angle annular dark-field images, whereas the center and right panels in $\mathrm{d}$ show the elemental mapping by energy-dispersive X-ray spectroscopy. Arrows in panel a show pore size (= $20 \mathrm{~nm})$ replicated from skeletal nanoporous copper, while panel b and c shows the finer porous structure of platinum.

Figure 3. (a) Energy-dispersive X-ray spectroscopy results and (b) X-ray diffraction patterns of bimodal nanoporous platinum before and after copper dissolution. Pattern for Pt black is shown for comparison in (b).

Figure 4. (a) Cyclic voltammetry curves for bimodal nanoporous platinum before and after copper dissolution. The scan rate was $10 \mathrm{mV} \mathrm{s}^{-1}$ and the electrolyte was $0.1 \mathrm{~mol} \mathrm{~L}^{-1} \mathrm{H}_{2} \mathrm{SO}_{4}$. (b) Polarization curves for rotation disk electrodes that load bimodal nanoporous platinum before and after copper dissolution. The scan rate was $10 \mathrm{mV} \mathrm{s}^{-1}$ and the electrolyte was $0.1 \mathrm{~mol} \mathrm{~L}^{-1}$ $\mathrm{H}_{2} \mathrm{SO}_{4}$. 
1. Nanoporous $\mathrm{Cu}$

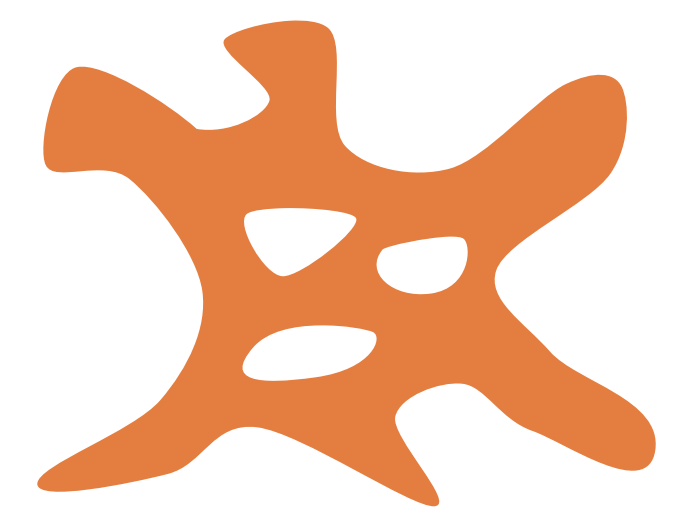

(a)

Figure 1

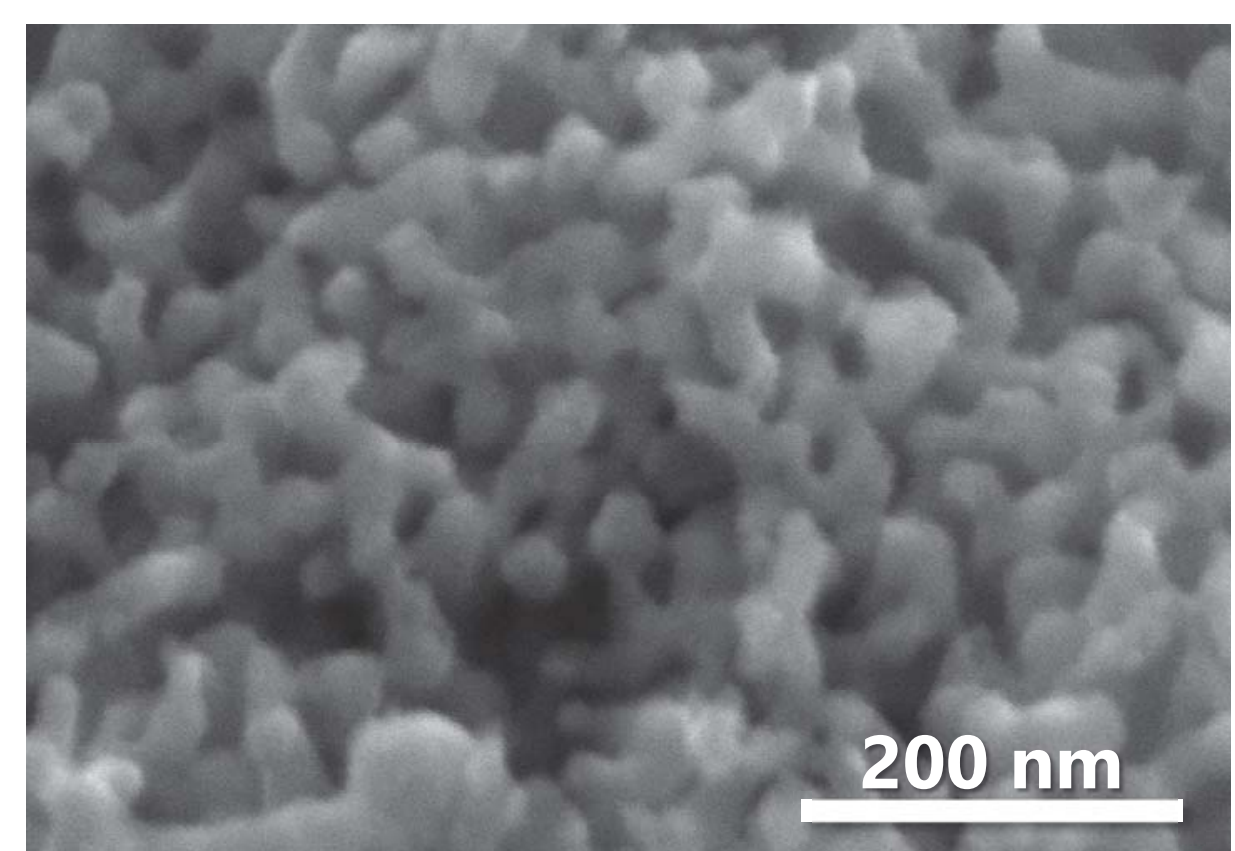

(b)

(a)

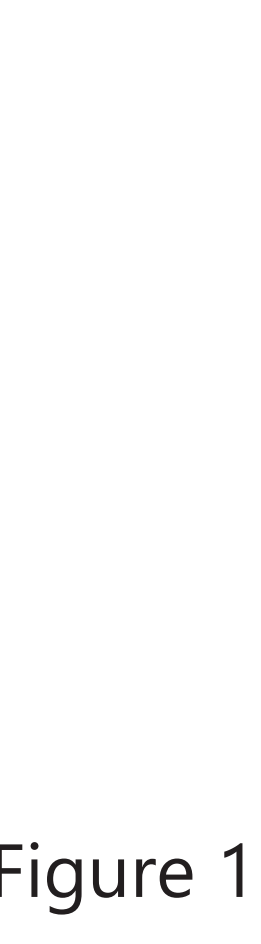

\section{$200 \mathrm{~nm}$}

2. Galvanic replacement by $\mathrm{Pt} \quad$ 3. Cu dissolution
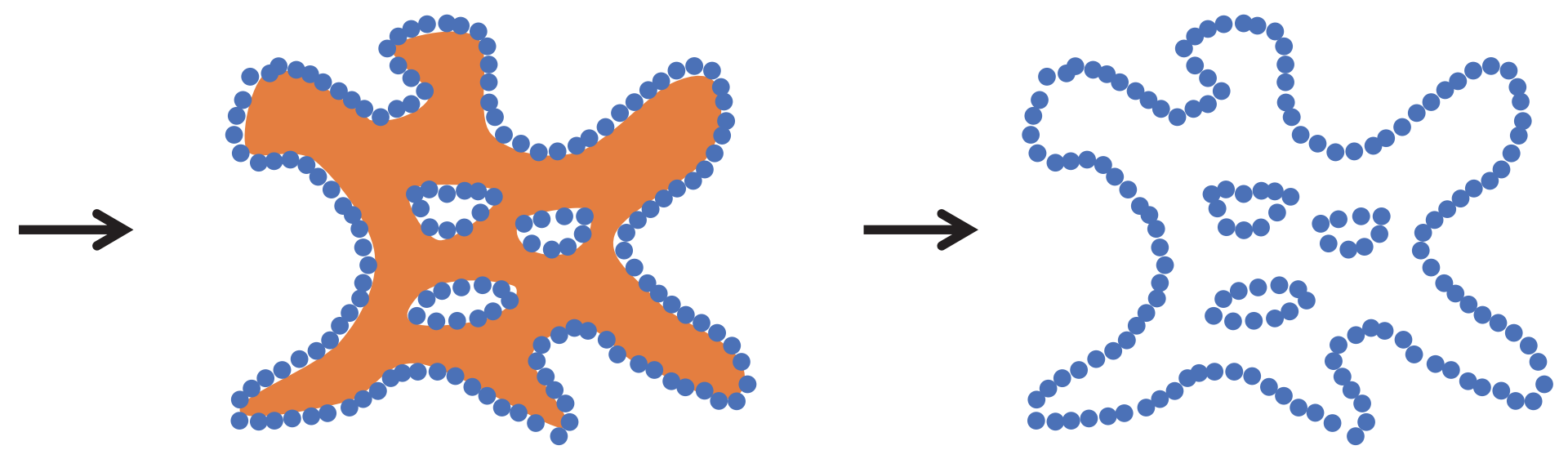


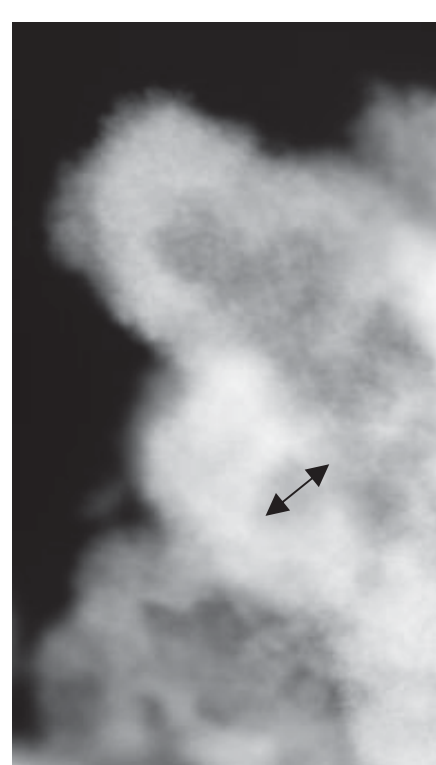

(a)

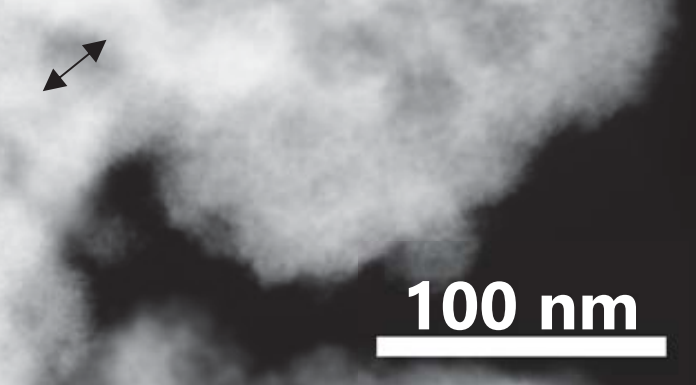

$20 \mathrm{~nm}$

(b)
$10 \mathrm{~mm}$

(c)

\begin{abstract}
BF
\end{abstract}
-10 ת.

(d)
$\mathrm{Cu}$

Goum

s.
Pt

$10 \mathrm{~nm}$ 
Figure 3
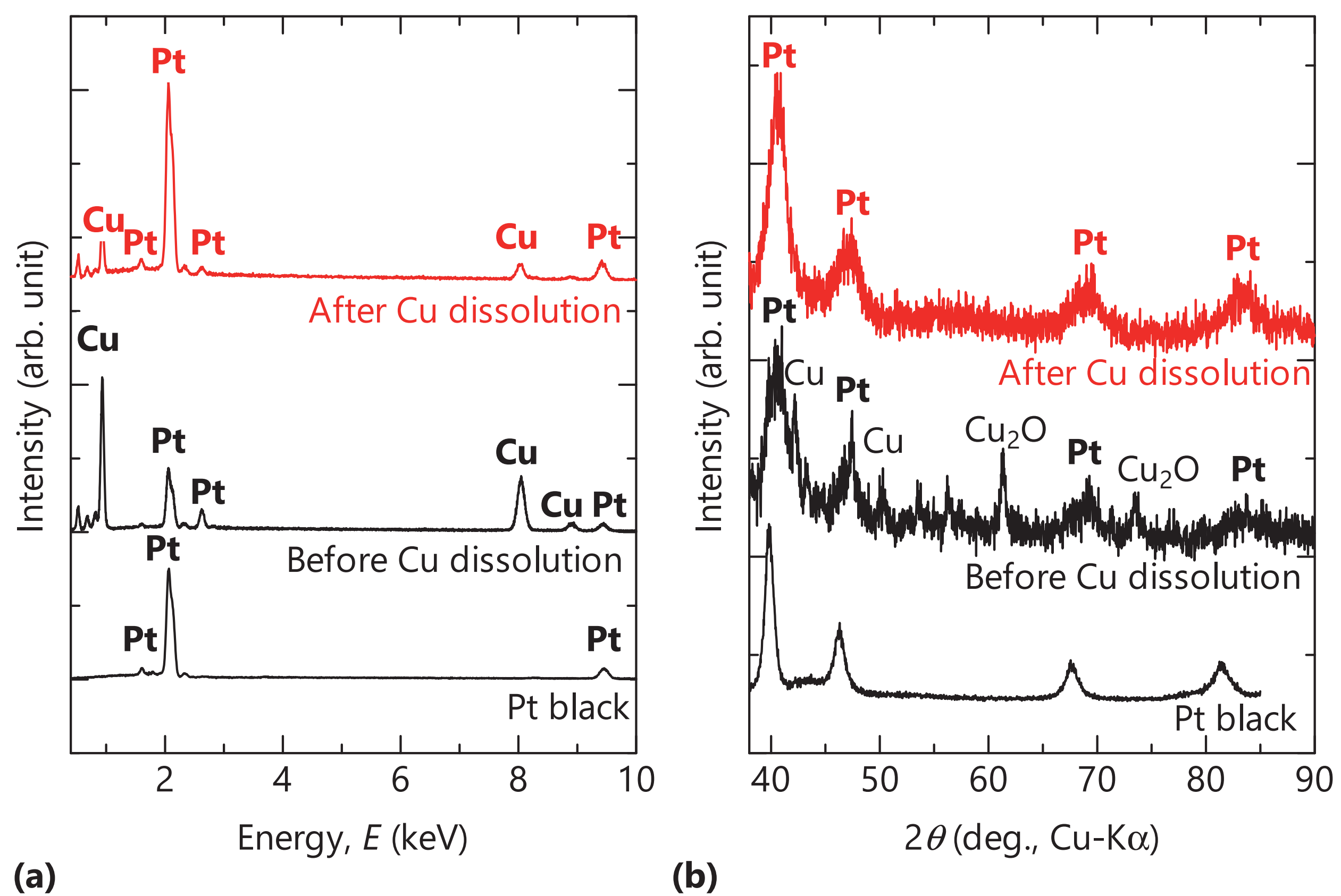

(b) 
Figure 4
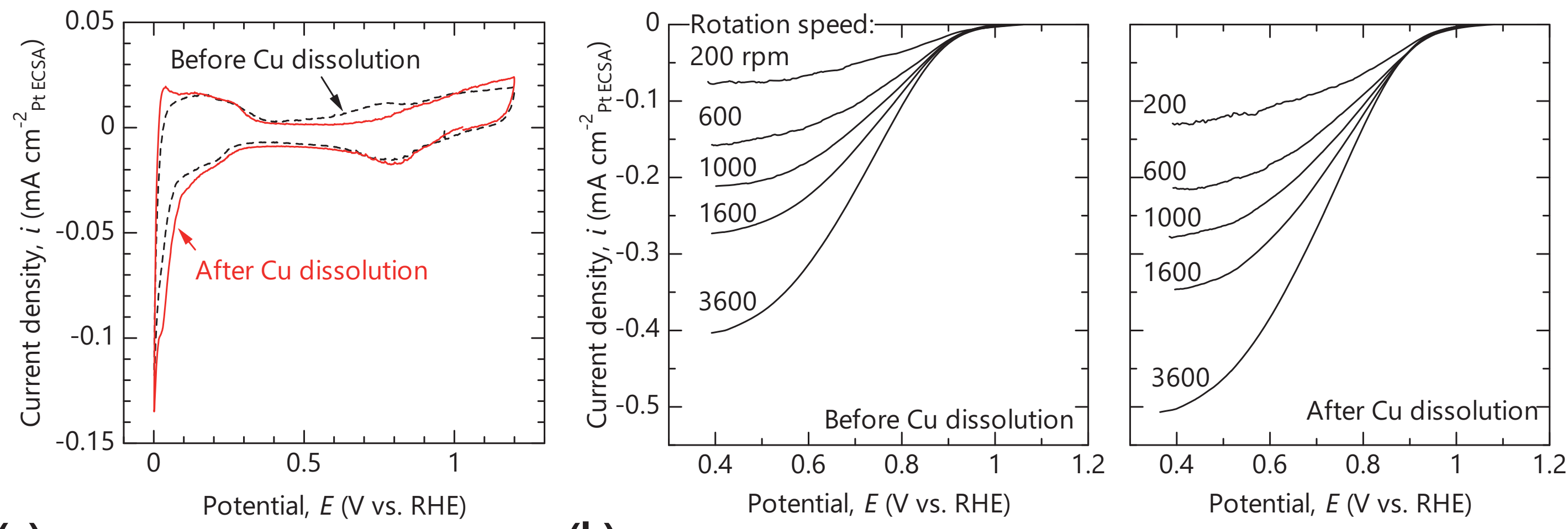

(a)

(b) 